\title{
ScreenPro FH: From the Czech MedPed to International Collaboration. ScreenPro FH Is a Participating Project of the EAS-FHCS
}

\author{
R. CESKA ${ }^{1,2}$, T. FREIBERGER ${ }^{3,4}$, M. VACLOVA ${ }^{1}$, T. ALEKSICOVA ${ }^{2}$, L. VOTAVOVA $^{2}$, \\ M. VRABLIK ${ }^{1}$
}

${ }^{1}$ Centre for Preventive Cardiology, Third Department of Internal Medicine, University General Hospital and the First Faculty of Medicine, Charles University, Prague, Czech Republic, ${ }^{2}$ ScreenPro FH Project, Prague, Czech Republic, ${ }^{3}$ Molecular Genetics Laboratory, Centre for Cardiovascular Surgery and Transplantation, Brno, Czech Republic, ${ }^{4}$ Medical Faculty, Masaryk University, Brno, Czech Republic

Received December 30, 2016

Accepted January 10, 2017

\section{Summary}

This article describes the evolution of our understanding of familial hypercholesterolemia (FH) in the Central, Eastern, and Southern Europe (CESE) region, and the dissemination of this understanding to other countries. Using the ScreenPro FH project as an example, we would like to illustrate the progression from national objectives, to regional networking and, finally, to international collaboration via the Familial Hypercholesterolemia Studies Collaboration (FHSC) project under the leadership of the European Atherosclerosis Society (EAS). It is essential to improve our ability to diagnose FH. In this regard, the EAS and its FHSC project must be commended for their educational and organizational activities which, above all, are dedicated to the creation of a global FH patient registry. In the CESE region, $\mathrm{FH}$ diagnostics and treatment situation are markedly different than in Western Europe or North America. Since the Czech MedPed project (Make Early Diagnoses to Prevent Early Deaths in Medical Pedigrees) has been so successful (with results not only comparable to, but, for some parameters, even surpassing the results of many Western countries) we decided to apply the Czech experience to the CESE region. Thus, the ScreenPro $\mathrm{FH}$ project was created. The aim of ScreenPro FH is to create a specialist network in the CESE region. The primary objective of the ScreenPro FH project was to dramatically reduce the number of premature deaths due to clinical complications of atherosclerosis in $\mathrm{FH}$ patients. At present, ScreenPro $\mathrm{FH}$ comprises 18 member countries with a total population of
$500,000,000$; which, in terms of the $\mathrm{FH}$ population, represents 1-2 million patients.

\section{Key words}

MedPed • ScreenPro FH • FHSC • Familial hypercholesterolemia • Statin intolerance

\section{Corresponding author}

M. Vaclova, Centre for Preventive Cardiology, Third Department of Internal Medicine, University General Hospital and the First Faculty of Medicine, U Nemocnice 2, Prague 2, Czech Republic. E-mail: vaclova.martina@seznam.cz

\section{Introduction}

At present, $\mathrm{FH}$ is primarily (but not exclusively) considered to be a receptor disease. It is a monogenic disease transmitted through autosomal dominant inheritance, and stems from either an LDL-receptor defect, apolipoprotein B mutation (Familial defective APOB-FDB), or PCSK9 (Proprotein convertase subtilisin/kexin type 9) mutations (Innerarity et al. 1987, Hobbs et al. 1992, Goldstein et al. 2001).

FH is an example of a disease that, by its very nature, allows us to study the relationship between lipid metabolism, especially low density lipoprotein cholesterol (LDL-C), and atherosclerosis, as well as 
premature manifestation of cardiovascular disease. Unfortunately, and most importantly, it is also the most significant clinical syndrome which, through congenitally elevated LDL-C concentrations, leads to the development of coronary artery disease (CAD) and other manifestations of atherosclerotic vascular disease (ASVD). FH is underestimated, underdiagnosed and undertreated (Nordestgaard et al. 2013).

Many international projects have sought to create uniform doctrines for the screening, diagnosis, and treatment of $\mathrm{FH}$ patients. However, ultimately these efforts have always been highly individualized, and dependent upon the activities of clinicians.

The Czech Republic's (CZ) MedPed (Make Early Diagnoses to Prevent Early Deaths in Medical Pedigrees) project was first launched in the 1990s. Thanks to the efforts of the Czech Society for Atherosclerosis (www.athero.cz) and several outstanding personalities, the $\mathrm{CZ}$ project continued to carry on successfully even when the MedPed project was no longer active at the international level. As a result of this continued diligence and dedication, the $\mathrm{CZ}$ is currently positioned at the leading edge of $\mathrm{FH}$ screening and diagnostics. Detailed information regarding the Czech MedPed project has been described by Vrablik et al. (2017).

\section{The ScreenPro FH constitution}

Based on Czech MedPed experience, the international ScreenPro FH project was established at the end of 2014 in an effort to improve FH screening, diagnostics and treatment within the CESE region. Eighteen countries in the CESE region are active project participants (Fig. 1).

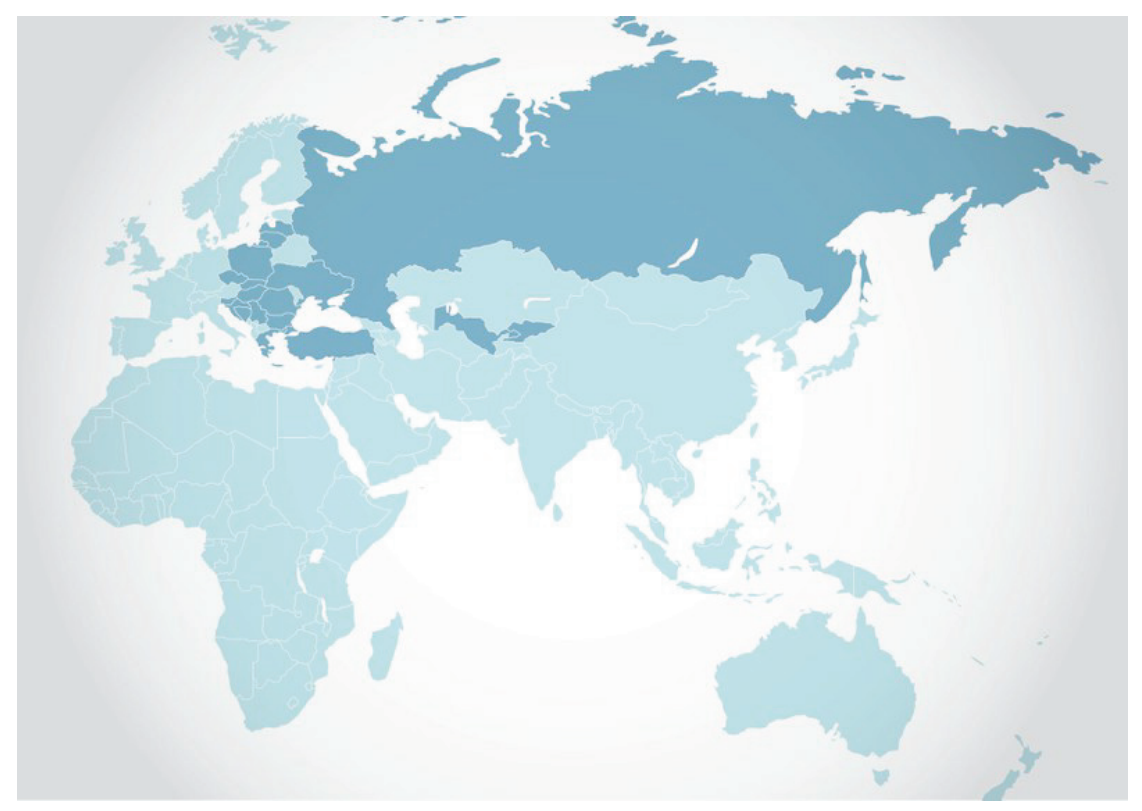

Fig. 1. Map of ScreenPro FH countries (Bosnia and Herzegovina, Bulgaria, Croatia, Czech Republic, Greece, Hungary, Kyrgyzstan, Latvia, Lithuania, Poland, Romania, Russia, Serbia, Slovakia, Slovenia, Turkey, Ukraine, Uzbekistan).

\section{Rationale}

Despite recent progress in diagnostics and treatments, FH remains a significant problem and a common risk factor for the premature development of CAD. The status of FH programs in each CESE country is quite different. One important project task is the harmonization and unification of the approaches used in these countries. Countries with more advanced FH screening programs can serve as an example for countries that have only just joined the project. The experience gained from the Czech, Slovakian, and Hungarian projects can be utilized in other countries where $\mathrm{FH}$ has not yet been significantly studied and monitored. One objective that could be very advantageous would be to prepare integrated, unified documents for use in all countries (following translation into the local language). Such documents would include general, scientific, and medical information; as well as forms and other documents (e.g. informed consent) and educational materials for patients. Likewise, it would also be beneficial, if permitted by the various healthcare systems, to adopt the same uniform guidelines for diagnostics and treatment (e.g. FH diagnostic criteria). 
Table 1. Dutch lipid clinic network diagnostic criteria for $\mathrm{FH}$.

\section{Family history}

i. First-degree relative with $\mathrm{CAD}, \mathrm{M}<55$ years, $\mathrm{F}<60$ years $\quad 1$

ii. First-degree relative with LDL-C above $95^{\text {th }}$ percentile for a given country 1

iii. First-degree relative with tendinous xanthoma and/or arcus lipoides 2

iv. Children under 18 years with LDL-C above $95^{\text {th }}$ percentile for a given country 2

\section{Personal clinical history}

i. Premature $\mathrm{CAD}, \mathrm{M}<55$ years, $\mathrm{F}<60$ years 2

ii. Premature peripheral or cerebral atherosclerosis, $\mathrm{M}<55, \mathrm{~F}<60$ years $\quad 1$

\section{Physical exam}

i. Tendinous xanthoma

ii. Arcus lipoides in patients under 45 years

\section{Biochemical exam}

LDL-C (mmol/l)

$>8.5$

\section{Molecular biology - diagnostic mutation testing}

i. Mutations in the genes encoding LDL-R, ApoB or PCSK9

CAD - coronary artery disease, M - male, F - female, LDL-C - LDL cholesterol, LDL-R - LDL receptor, ApoB - apolipoprotein B100, PCSK9 - proprotein convertase subtilisin/kexin type 9.

Dutch lipid network criteria (Table 1) (Van Aalst-Cohen et al. 2006) are generally accepted criteria for $\mathrm{FH}$ diagnostics. Therefore these criteria are recommended to all ScreenPro countries. The Dutch criteria are interpreted as follows: For a definite diagnosis of $\mathrm{FH}$, the subject must have more than 8 points; a probable diagnosis of $\mathrm{FH}$ requires 6-8 points; and a possible diagnosis of $\mathrm{FH}$ is indicated by 3-5 points. Patients who score 0-2 points most likely do not have $\mathrm{FH}$.

Such guidelines would have to be adopted via a consensus; at least, with regard to the selection of basic data that is to be monitored and recorded in national databases. This type of unification and harmonization would facilitate consistent, accurate evaluations of patient findings in a given region.

ScreenPro FH Certificate: All ScreenPro FH Project Leaders have received certificates from the National Centre of the ScreenPro FH Project.

The ScreenPro FH Project structure was established as follows: The leadership - Board of advisors/Administrative council - Country leaders. Regional centers are established in individual countries. A functional network exists in some countries (e.g. Czech
Republic, Slovakia, Poland, Hungary).

\section{ScreenPro FH activities}

Website

The ScreenPro FH Project website was developed in a basic format to serve as an operational platform both for the project as well as the participating countries. The website, which primarily focuses on $\mathrm{FH}$, provides educational materials pertaining to dyslipidemias and cardiovascular disease prevention. Participating countries (and any interested colleagues) can also access a short summary describing the diagnostic and therapeutic procedures for FH patients (Cuchel et al. 2014, Hopkins et al. 2011). The website also offers a photo gallery of patients with xanthomas and other FH manifestations (all images are provided courtesy of the Centre for Preventive Cardiology in Prague).

Results from participating countries are under development and they vary from country to country (i.e. very good in Czech Republic and Slovakia; good in Poland and Hungary, and Greece; and some countries are in the early stages of development, e.g. Uzbekistan, 
Kazakhstan). Just for basic information we can provide some data, number of centers at some countries as well as number of patients in local databases: Bosnia and Herzegovina 1 center (900 patients), Croatia 1 center (130 patients), Czech Republic 63 centers (7,001 patients), Greece 9 centers (40 patients), Hungary 22 centers, Kyrgyzstan 3 centers, Latvia 1 center (162 patients), Lithuania 5 centers (500 patients), Poland 9 centers (1,884 patients), Russia 17 centers (700 patients), Slovakia 20 centers (2,000 patients), Turkey 1 center (more than 1,000 patients), Ukraine 5 centers ( 81 patients) and Uzbekistan 13 centers (46 patients). More preliminary results are available at www.screenprofh.com.

Since statin intolerance is a significant issue in FH treatment (particularly treatment of high risk patients) we decided to include a "statin intolerance" paper in the educational section of the website.

The website is also a source of information regarding project structure, contacts, meetings, etc. The practical tools available for the unification and harmonization of FH patient care are quickly becoming (along with the educational content) the most important section of the website. Practical forms and documents such as FH patient cards, informed consent forms, educational information for patients, and information for families of FH patients, have been prepared and made available to all participating centers.

\section{Database}

ScreenPro FH has no ambition to own any country's data. Data from each country is the property of its own national network. The decision of whether, and how, data will be made available to the central registry is determined exclusively by national leadership. That said, the project website outlines what needs to be measured and what data should be collected, but other suggestions are "optional".

A database is also available that could be used by all countries at a later date (financial limitations mean that some countries only maintain paper records, or local electronic records). However, it is necessary to stress one more time, how important it is that participants use a unified data collection process that allows results from different countries to be combined and compared.

\section{The "Familial Hypercholesterolemia" textbook}

Since no medical textbooks on FH had ever been available on the local market, the FH textbook, published in Czech Republic, was translated into English, which made it accessible to all ScreenPro FH Project county leaders, as well as other interested physicians in the CESE region. This English version of the FH textbook was offered to all country leaders for translation. At present, the $\mathrm{FH}$ book is available in 6 languages (Czech, English, Ukrainian, Lithuanian, Serbo-Croatian, Russian); the Russian version, which has the potential to improve accessibility to the text in many countries, is also complete.

The project is under the auspices of the IAS and collaborates with other FH groups: EAS-FHSC. Last year, we started collaboration with the 10 Countries Study and we use the same questionnaire for our FH patients. The questionnaire is widely used in Australia and Asia, and it has been made available on our website for ScreenPro FH Project countries.

\section{Future activities: it is time to get practical}

Having had several ScreenPro FH Project Member meetings, we are now focusing on the practical aspects of the project. Our goal is to help member countries increase FH awareness in member countries and assist in the development of educational materials both for clinicians and patients (e.g. informed consent forms, educational materials for patients, questionnaires, etc.).

We have translated the FH patient card, which is important both for patients and physicians. It is advantageous for physicians because it allows them to review a patient's previous treatments and find information about cholesterol levels; and it also benefits patients by increasing awareness of their own health status.

Educational materials: A new list of educational materials will be made available, which includes basic materials for everyday clinical practice that have already been translated into English (e.g. Informed Consent, Letter for Relatives, Information for Patients, an FH Questionnaire, a Questionnaire for GPs, an FH patient Card, etc.).

Another important document that will soon be available is a set of Guidelines for the Establishment of a Lipid Clinic/Center, which details the essential steps needed for best practice care for FH patients.

\section{Laboratory collaboration}

ScreenPro FH has accepted a joint consensus statement from the EAS and European Federation of Clinical Chemistry and Laboratory Medicine concerning 
lipid profile determination. The paper will be available on the project website, and all country leaders will be made aware of this new consensus statement. This may require new agreements regarding laboratory protocols between ScreenPro FH members and the clinical chemistry and laboratory medicine specialists in their individual countries. Patient organizations play a valuable role in the comprehensive care of FH patients. ScreenPro FH is mapping the situation in individual countries; we want to support those patient organizations that already exist, and encourage the development of patient organizations in countries where they do not exist yet. In some cases, it may be possible for patients to join a "regional or international" patient organization, when local organizations are not available; which can provide education and support for FH patients and their families.

\section{Conclusion}

To summarize: 1) a basic ScreenPro FH project framework exists; 2) 18 countries from the CESE region are actively involved in the ScreenPro FH Project; and 3) a network of lipid centers is under development in all participating countries. Moreover, local national databases are growing. The website is now functional and available to project members, as well as other interested medical specialists. ScreenPro FH Project resources (such as the educational content of the website and the availability of the FH textbook in English and other languages), regular country project-leader meetings, and FH awareness itself, are all increasing in the CESE region.

\section{Conflict of Interest}

There is no conflict of interest.

\section{Acknowledgements}

Supported by Ministry of Health of the Czech Republic, grants nr. 15-28876A, 15-28277A, all rights reserved; and by IAS - Pfizer IGLC Grant.

\section{References}

CUCHEL M, BRUCKERT E, GINSBERG HN, RAAL FJ, SANTOS RD, HEGELE RA, KUIVENHOVEN JA, NORDESTGAARD BG, DESCAMPS OS, STEINHAGEN-THIESSEN E, TYBJÆRG-HANSEN A, WATTS GF, AVERNA M, BOILEAU C, BORÉN J, CATAPANO AL, DEFESCHE JC, HOVINGH GK, HUMPHRIES SE, KOVANEN PT, MASANA L, PAJUKANTA P, PARHOFER KG, RAY KK, STALENHOEF AFH, STROES E, TASKINEN MR, WIEGMAN A, WIKLUND O, CHAPMAN MJ: Homozygous familial hypercholesterolaemia: new insights and guidance for clinicians to improve detection and clinical management. A position paper from the Consensus Panel on Familial Hypercholesterolaemia of the European Atherosclerosis Society. Eur Heart J 35: 2146-2157, 2014.

GOLDSTEIN JL, HOBBS HH, BROWN MS: Familial hypercholesterolemia. In: The Metabolic and Molecular Bases of Inherited Disease. 8th edition, SCRIVER CR, BEAUDET AL, SLY WS, VALLE D (eds), McGraw-Hill, New York, 2001, pp 2863-2914.

HOBBS HH, BROWN MS, GOLDSTEIN JL: Molecular genetics of the LDL receptor gene in familial hypercholesterolemia. Hum Mutat 1: 445-466, 1992.

HOPKINS PN, TOTH PP, BALLANTYNE CM, RADER DJ: Familial hypercholesterolemias: prevalence, genetics, diagnosis and screening recommendations from the National Lipid Association Expert Panel on Familial Hypercholesterolemia. J Clin Lipidol 5 (3 Suppl): S9-S17, 2011.

INNERARITY TL, WEISGRABER KH, ARNOLD KS, MAHLEY RW, KRAUSS RM, VEGA GL, GRUNDY SM: Familial defective apolipoprotein B-100: low density lipoproteins with abnormal receptor binding. Proc Natl Acad Sci USA 84: 6919-6923, 1987.

NORDESTGAARD BG, CHAPMAN MJ, HUMPHRIES SE, GINSBERG NH, MASANA L, DESCAMPS OS, WIKLUND O, HEGELE RA, RAAL FJ, DEFESCHE JC, WIEGMAN A, SANTOS RD, WATTS GF, PARHOFER KG, HOVINGH GK, KOVANEN PT, BOILEAU C, AVERNA M, BORÉN J, BRUCKERT E, CATAPANO AL, KUIVENHOVEN JA, PAJUKANTA P, RAY K, STALENHOEF AF, STROES E, TASKINEN MR, TYBJÆRG-HANSEN A; EUROPEAN ATHEROSCLEROSIS SOCIETY CONSENSUS PANEL: Familial hypercholesterolaemia is underdiagnosed and undertreated in the general population: guidance for clinicians to prevent coronary heart disease: consensus statement of the European Atherosclerosis Society. Eur Heart J 34: 3478a-3490a, 2013. 
VAN AALST-COHEN ES, JANSEN AC, TANCK MW, DEFESCHE JC, TRIP MD, LANGSBERG PJ, STALENHOEF AF, KASTELEIN JJ: Diagnosing familial hypercholesterolaemia: the relevance of genetic testing. Eur Heart J 27: 2240-2246, 2006.

VRABLIK M, VACLOVA M, TICHY L, SOSKA V, BLAHA V, FAJKUSOVA L, CESKA R, SATNY M, FREIBERGER T: Familial hypercholesterolemia in the Czech Republic: more than 17 years of systematic screening within the MedPed project. Physiol Res 66 (Suppl 1): S1-S9, 2017. 